Disponível em

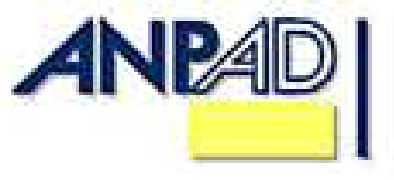

http://www.anpad.org.br/rac

RAC, Rio de Janeiro, v. 16, n. 3, art. 1, pp. 342-359, Maio/Jun. 2012

(c) EY-NG

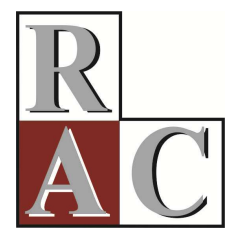

\title{
O Jogo de Empresas no Processo de Aprendizagem em Administração: o Discurso Coletivo de Alunos
}

\section{Collective Student Discourse about Business Games in the Management Learning Process}

\author{
Gustavo da Silva Motta * \\ E-mail: gustavosmotta@vm.uff.br \\ Universidade Federal Fluminense - UFF \\ Volta Redonda, RJ, Brasil. \\ Daniel Reis Armond de Melo \\ E-mail: armond@ufam.edu.br \\ Universidade Federal do Amazonas - ICET/UFAM \\ Manaus, AM, Brasil. \\ Roberto Brazileiro Paixão \\ E-mail: roberto.brazileiro@ufba.br \\ Universidade Federal da Bahia - EA/UFBA \\ Salvador, BA, Brasil.
}

* Endereço: Gustavo da Silva Motta

Rua Desembargador Ellis Hermydio Figueira, 783, Aterrado, Volta Redonda/RJ, 27213-415.

Copyright (C) 2012 RAC. Todos os direitos, até mesmo de tradução, são reservados. É permitido citar parte de artigos sem autorização prévia, desde que seja identificada a fonte. 


\title{
Resumo
}

Este trabalho visa a analisar qual a percepção dos alunos a respeito do significado dos jogos de empresas no processo de aprendizagem em Administração. Os jogos têm-se destacado tanto por sua ampla utilização no ambiente acadêmico quanto no ambiente empresarial, pela possibilidade de vivência simulada de situações empresariais, nas quais é necessária a tomada de decisão. O que se observa, entretanto, é que as pesquisas ainda são muito frágeis na tentativa de comprovar a validade dos jogos como uma prática educacional capaz de agregar conhecimento à formação do administrador, ou seja, de contribuir para uma aprendizagem significativa. Assim, foi desenvolvida uma pesquisa com 72 alunos dos cursos de graduação em Administração e de especialização em Administração ou áreas correlatas (lato sensu), submetidos à técnica de jogos de empresas. Os dados coletados foram analisados, qualitativa e quantitativamente, de acordo com a metodologia do Discurso do Sujeito Coletivo (DSC), desenvolvida por Lefevre e Lefevre (2003, 2005). Foi possível constatar que a percepção a respeito do jogo de empresas para os alunos está fortemente integrada às contribuições do mesmo para o processo de aprendizagem em administração. Alguns foram os fatores identificados como as principais contribuições: (a) o auxílio no treinamento para o processo decisório, encargo característico do administrador; (b) a vivência simulada das atividades empresariais; (c) o desenvolvimento de habilidades interpessoais para o trabalho em equipe; e (d) a aplicação dos conhecimentos adquiridos ao longo do curso de administração.

Palavras-chave: processo de aprendizagem; jogos de empresas; discurso do sujeito coletivo.

\begin{abstract}
This paper aims to analyze the perception students have about the meaning of business games in the management learning process. Business games are as useful in the academic environment as they are in the commercial environment, as they offer simulated experience of business situations and associated decision-making. Research that proves the validity of such games as an educational practice able to add knowledge to management training and contribute a meaningful learning experience is still incipient. Thus, this research was undertaken with 72 students from undergraduate and specialization courses in Management and related areas who have taken part in business games. The collected data was analyzed, qualitatively and quantitatively, using the Collective Subject Speech (CSS) method, developed by Lefevre and Lefevre $(2003,2005)$. What emerged is that the meaning of the business games for the students is related to its contributions to the management learning process. Some factors were identified as the main contributions: (a) the aid in developing decision-making skills, an integral characteristic of management roles; (b) the simulated experience of business activities; (c) the development of interpersonal abilities for teamwork; and (d) the application of knowledge acquired during Management courses.
\end{abstract}

Key words: learning process; business games; collective subject speech. 


\section{Introdução}

Segundo dados no Instituto Nacional de Estudos e Pesquisas Educacionais Anísio Teixeira (INEP, 2006), havia 768.693 alunos matriculados em cursos de graduação presenciais de Gerenciamento e Administração em todo o Brasil, no ano de 2006. Esse dado corresponde a 16,4\% do total de alunos matriculados nos cursos de graduação presenciais do país. Adicionando a expansão de cursos de graduação não presenciais, além da pós-graduação (stricto sensu e lato sensu) e da educação executiva, observa-se que nenhuma outra área de ensino assumiu tamanha dimensão em nosso país como a de Administração, como já foi observado também por Bertero (2006).

Essa expansão de cursos de Administração não necessariamente está associada à melhoria dos processos de ensino-aprendizagem. Projetos como o Programa de Capacitação Docente em Administração (PCDA), da Associação Nacional de Pós-graduação e Pesquisa em Administração (ANPAD) evidenciam a preocupação de professores e pesquisadores da área de gestão em relação aos aspectos contemporâneos de ensino-aprendizagem em Administração.

Uma das iniciativas que visa à melhoria do processo educacional brasileiro em Administração foi a introdução, a partir da década de 1970, dos jogos de empresas como técnica de ensino nos cursos universitários, assim relatado por Goldschmidt (1977), numa das primeiras experiências brasileiras, ocorrida na Escola de Administração de Empresas de São Paulo (EAESP/FGV). Desde então, essa técnica tem-se destacado, tanto no ambiente acadêmico quanto no empresarial, pela possibilidade de vivência simulada de situações empresariais nas quais é necessária a tomada de decisão.

Uma rápida revisão da literatura permite verificar que a maioria dos autores enfoca seus estudos e pesquisas sobre jogos de empresas na capacidade de treinamento para a tomada de decisões. Segundo Peixoto, Veloso e Lopes (2003), poucos são os autores que demonstram preocupação com os aspectos pedagógicos dos jogos de empresas e propõem que esse enfoque permite a articulação com os princípios teóricos da Administração e o alcance de objetivos didáticos. Já Paixão, Bruni e Carvalho (2007) destacam que as publicações que antes tinham caráter mais explicativo passaram para pesquisas sobre as relações de ensino-aprendizagem proporcionadas pelos jogos de empresas, e já apontam para estudos empíricos que utilizam a metodologia como laboratórios de gestão empresarial.

Essa ótica pedagógica torna-se particularmente relevante quando se constata, por meio de inúmeras pesquisas (Lacruz \& Villela, 2006; Lopes, 2001; Nagamatsu, Fedichina, Gozzi, \& Boldrin, 2006; Olivier \& Rosas, 2004; Sauaia, 1995; Sheizi \& Santos, 2003), inclusive esta, a satisfação de alunos e professores com a utilização de jogos de empresas enquanto técnica de ensino-aprendizagem. O que se observa, entretanto, é que as atuais pesquisas ainda são muito frágeis na tentativa de comprovar a validade dos jogos como uma prática educacional capaz de agregar conhecimento à formação do administrador, ou seja, de contribuir para uma aprendizagem significativa.

Nesse sentido, Katz (1974) descreve os três tipos de competências necessárias para que o administrador realize seu trabalho eficazmente: as técnicas, as humanas, e as conceituais. Para esse autor, competência implica em habilidades que podem ser desenvolvidas, não necessariamente inatas, e que se manifestam por meio do desempenho e não do potencial. Assim, Katz (1974) defende que o processo de formação de administradores deve visar à ação efetiva desse profissional, em variadas circunstâncias.

Dessa forma, o objetivo deste trabalho é analisar, a partir do discurso coletivo de alunos de graduação e pós-graduação submetidos à técnica de jogos de empresas, qual a percepção a respeito dos jogos no processo de aprendizagem em Administração. 


\section{Jogos de Empresas no Ensino de Administração}

Antes de iniciar uma apresentação sobre a definição, a evolução e a aplicação dos jogos de empresas nos cursos de Administração, faz-se mister a diferenciação entre os conceitos de simulador e de jogo de empresas. Para Sauaia (2006), o "simulador é a ferramenta que permite a aplicação do jogo de empresas, o qual se refere ao processo de gestão simulada, em que os participantes da dinâmica possuem papel ativo na tomada de decisões" (Sauaia, 2006, p. 4). Assim, o simulador tem sua aplicação limitada à operacionalização de variáveis, e a complexidade fica atribuída a partir da dinâmica do jogo com o ambiente de incerteza característico das decisões dos adversários e do comportamento do grupo no processo de negociação de uma decisão única.

De acordo com Li e Baillie (1993), o primeiro simulador utilizado com administradores foi desenvolvido pela American Management Association em meados da década de 1950. No mesmo ano, a Universidade de Washington iniciou o uso de um simulador chamado TOP MAN, desenvolvido por Schrieber. No Brasil, as pesquisas com a utilização de jogos de empresas iniciaram-se na década de 70, com os trabalhos de Tanabe (1973), Goldschmidt (1977) e Warschauer (1977). Na década de 80, o Programa de Pós-graduação em Engenharia de Produção da Universidade Federal de Santa Catarina iniciou um centro de desenvolvimento de jogos para aplicações em educação e pesquisa (Lopes, 2001), facilitado, em grande parte, pelo desenvolvimento dos computadores pessoais e da microinformática em geral (Mendes, 2000). Na Faculdade de Economia e Administração da Universidade de São Paulo, foram desenvolvidas quatro pesquisas acadêmicas no programa de pósgraduação stricto sensu, importantes para o desenvolvimento do tema, a saber: as pesquisas de Beppu (1984), Martinelli (1987) e de Sauaia (1990, 1995). Contudo, a utilização dos jogos de empresas no Brasil ainda era incipiente, quando comparada com a que se fazia nos Estados Unidos (Sauaia, 1995). Atualmente, inúmeras são as faculdades de Administração que contam, em seu currículo, com uma disciplina denominada Jogos de Empresas. Mesmo esta não sendo uma condição sine qua non para a aplicação de tal técnica, demonstra-se uma preocupação institucional em integrar a dinâmica à formação dos futuros gestores.

Goldschmidt (1977) afirma que "o jogo de empresas se aproxima de um estudo de caso, onde adicionamos duas variáveis: uma é o feedback - o retorno das informações; a outra é a dimensão temporal que, geralmente, os casos não têm" (p. 43). Esta diferença ilustra as principais vantagens de utilização dos jogos de empresas no processo de ensino-aprendizagem em gestão: a capacidade de observar as consequências de suas decisões, e a possibilidade de se aprender com os erros. Li e Baillie (1993) ainda apontam o grande estímulo à participação dos alunos como outra vantagem da aplicação de jogos de empresas. Entretanto Sauaia (2006), corroborando Li e Baillie (1993), assevera que a abordagem dos jogos não auxilia a aquisição de conhecimentos teórico e aplicado, havendo ainda a possibilidade de se obter um bom desempenho no jogo através da sorte.

Baseando-se em Libâneo (1994) e Gil (1997), e também de acordo com Saviani (1998), a aplicação de jogos de empresas para a formação de administradores pode ser pensada como um elemento da didática, mais especificamente, uma técnica de ensino (simulação). Ou seja, um conjunto de procedimentos adotados pelo docente para conduzir os alunos no alcance dos objetivos educacionais, por meio do aprendizado dos diversos conteúdos necessários para a sua formação profissional. Dessa feita, ao se utilizar jogos de empresas como técnica de ensino, os recursos necessários são: o simulador (eletrônico ou não), as regras do jogo e o modelo econômico. A escolha de se trabalhar com jogos de empresas é baseada em princípios da aprendizagem baseada em problemas (Ribeiro, 2005) ou PBL (do inglês, Problem-based Learning) e da aprendizagem vivencial (Kolb, 1984). Ambas apresentam uma proposta construtivista, isto é, busca-se fugir do tradicionalismo, no qual o aluno tem o papel passivo de assistir à exposição do professor. A aplicação de jogos de empresas permite ao aluno buscar e manipular informações de acordo com os seus próprios interesses e percepções, assumindo papel ativo no processo de ensino-aprendizagem, e a responsabilidade pela construção do seu próprio conhecimento (Sauaia, 1995). 
Tem-se, entretanto, que atividades como essa exigem posturas diferenciadas de professor e aluno. Este último passa de um papel secundário, de receptor passivo, para participante ativo do processo, o que nem sempre é habitual para o estudante, ocasionando, por vezes, um estranhamento. Há um processo de desenvolvimento da autonomia deste, que passa a ter responsabilidade direta sobre o seu aprendizado. A intenção é transformá-los em aprendizes por toda a vida, requisito mais que necessário em uma sociedade em rápida transformação (Sauaia, 2008).

De acordo com Sauaia (1995), na aprendizagem vivencial, o professor deixa de ser o centro do processo, posição que passa a ser ocupada pelo educando. $\mathrm{O}$ trabalho em grupo prevalece sobre o trabalho eminentemente expositivo do ensino tradicional. Os participantes sentem-se motivados, em um ambiente que os desafia e que, ao mesmo tempo, acolhe-os, combinando momentos de disputa e de cooperação. Isso facilita um maior envolvimento dos participantes na busca da aprendizagem.

Rhem (1998 como citado em Ribeiro, 2005) afirma que trabalhar com atividades em grupos de forma colaborativa não é algo com que a maioria dos docentes tenha experiência. Ressalta-se, ainda, a possível dificuldade de o professor, no momento da escolha/concepção do simulador, ter o instrumento que seja autêntico e relevante aos alunos em seu próprio contexto socioambiental de maneira que estimule a participação deles.

Observa-se ainda que, com os jogos de empresa, em virtude do interesse dos alunos em obter bom resultado na simulação, em ganhar o jogo (Goldschmidt, 1977), acaba por tornar-se difícil a avaliação da aprendizagem, como ressaltado por Stahl e Lopes (2004). É preciso saber diferenciar o desempenho na simulação e a aprendizagem desenvolvida, ou seja, reconhecer que é possível aprender com os erros. Entretanto, é comum que os professores estabeleçam os critérios de aprovação na atividade baseados no desempenho da equipe no jogo, o que segundo Stahl e Lopes (2004), é um equívoco.

\section{A Aprendizagem Baseada em Problemas}

A Aprendizagem Baseada em Problemas (PBL) é uma metodologia de ensino-aprendizagem que se desloca de tradicionais abordagens instrutivistas, centradas no papel do professor, para uma abordagem construtivista, centrada no papel do estudante. Ribeiro (2005) relata que sua origem data do final dos anos 1960, na escola de medicina da Universidade McMaster no Canadá, como resposta à insatisfação dos alunos em relação à quantidade de conteúdo percebido como irrelevante à prática médica, e à incapacidade de aplicação de informações a um diagnóstico. Questão semelhante já foi observada e criticada, há mais de duas décadas, no campo da administração no Brasil (Zajdsznajder, 1981).

Para Anderson e Lawton (2007), o processo pedagógico, através da PBL, inicia-se com a apresentação ao aluno de um problema, fundado na ideia de que este deve preceder as respostas. Assim, os estudantes têm a oportunidade de, reconhecendo suas deficiências de conhecimento, identificar conceitos e habilidades pertinentes à solução do problema proposto. Espera-se, desta forma, uma maior motivação para a compreensão dos conteúdos da disciplina, além da capacidade de articulação da teoria à prática.

Em geral, a PBL é definida como um método de ensino que utiliza problemas como contextos para a aquisição de conhecimentos básicos e de habilidades para a solução de problemas, por parte dos estudantes (Banta, Black, \& Kline, 2000). Para alguns autores, a PBL "é um método caracterizado pelo uso de problemas do mundo real" (Ribeiro \& Mizukami, 2004, p. 90). Já outros preferem fazer uma distinção entre a PBL e a Metodologia da Problematização. Berbel (1998) alerta para o fato de que, na primeira, os problemas são elaborados por especialistas, com o objetivo de cobrir os conhecimentos essenciais do currículo e que, na segunda, os problemas são extraídos da realidade pela observação realizada pelos aprendizes. Independente de tal distinção teórica, observam-se dois 
aspectos comuns a todas as definições: a abordagem centrada no papel do aprendiz e o enfoque do curso no uso de problemas.

O uso de problemas com finalidade pedagógica suscita a discussão do que pode ser considerado um bom problema, ou seja, a questão da qualidade do problema. Anderson e Lawton (2007) estabelecem dois critérios necessários para a definição do problema em projetos de PBL: capacidade de estimular os estudantes à busca do aprendizado e requerer deles a pesquisa e a articulação dos conceitos básicos do curso para a solução do problema.

Observa-se que a prática educacional dos jogos de empresas, que se tem tornado comum nos cursos de gestão, em maior ou menor grau, a depender da experiência, atende aos critérios de um projeto de PBL. Nesse sentido, questões como a criação da empresa simulada, a tomada de decisões relativas às diversas variáveis envolvidas (marketing, produção, recursos humanos, finanças, etc.), o comportamento das outras equipes competidoras, as variações do cenário econômico, dentre outras, configuram-se como problemas apresentados aos alunos para que estes encontrem respostas, dentre inúmeras possibilidades. Assim, os aprendizes são estimulados a articular conhecimentos adquiridos (muitas vezes de forma fragmentada) ao longo do curso, praticando a tomada de decisões e desenvolvendo habilidades interpessoais.

\section{A Aprendizagem Vivencial}

Outra abordagem altamente aderida ao desenvolvimento cognitivo através da aplicação de jogos de empresas é a da aprendizagem vivencial. Segundo Kolb (1984), a aprendizagem vivencial considera o aprendizado como um processo, no qual o conhecimento é produzido através da transformação da experiência. Dessa forma, é possível extraírem-se três aspectos fundamentais da aprendizagem vivencial. Inicialmente, observa-se uma ênfase no processo e na aprendizagem, em oposição à ênfase no conteúdo e no resultado, característicos do ensino tradicional. Segundo, o conhecimento é visto como um processo de transformação que é continuamente criado e recriado, em lugar de um produto acabado que deve ser adquirido ou transmitido. Finalmente, a aprendizagem vivencial reconhece que os indivíduos aprendem de diferentes formas e respondem distintamente a um mesmo estímulo (Kolb, 1984; Pereira, 2005; Thorelli, 2001).

Para Kolb (1984), há quatro capacidades básicas de que o aprendiz precisa dispor para efetivar seu aprendizado. Tais capacidades se organizam em quatro fases, descritas a seguir, e que compõem o Ciclo da Aprendizagem Vivencial ou Ciclo de Kolb (Figura 1):

1. Experiência Concreta: é a orientação cujo enfoque reside no envolvimento com experiências e no tratamento de questões humanas. Enfatiza o sentir em oposição ao pensar e interessa-se por questões particulares em lugar de generalizações.

2. Observação Reflexiva: nesta, o fim é a compreensão, através da observação e da descrição cuidadosa e imparcial, do significado das ideias e dos fatos. Privilegia o refletir em oposição ao agir e interessa-se na verdade absoluta ou em como as coisas são e não por seu funcionamento.

3. Conceituação Abstrata: o enfoque está aqui no uso da lógica, das ideias e dos conceitos. Privilegia o pensar em oposição ao sentir e interessa-se por teorias gerais em lugar de questões particulares.

4. Experimentação Ativa: é a orientação em que o foco está em influenciar ativamente as pessoas e mudar as situações. Enfatiza o agir em oposição ao refletir e interessa-se pragmaticamente no que deve ser feito e não na busca pela verdade absoluta.

Para a construção desse modelo quadrifásico, Kolb (1984) parte do princípio de que a aprendizagem pode ser entendida como um processo bidimensional. A primeira dimensão relaciona-se com a percepção da informação e, a segunda, com o processamento dela. Dessa forma, os extremos do 
continuum que representa a dimensão da percepção são formados pelos termos sentir e pensar. Já os extremos que representam a dimensão processamento são formados pelas expressões refletir e agir. Esta estrutura bidimensional e quadrifásica está representada na Figura 1.

Sauaia (2008) apresenta uma sugestão para a aplicação dos jogos de empresas, obedecendo às fases do Ciclo de Kolb (1984). Dessa forma, as regras econômicas do simulador e a materialização da experiência através da tomada de decisões inicial representariam a experiência concreta. A observação reflexiva seria representada pela análise dos resultados e a observação dos desvios entre as metas planejadas e realizadas. Uma sessão de debates sobre os diversos desempenhos da turma pode levar à compreensão dos resultados, a partir de uma revisão conceitual dos modelos teóricos, o que caracterizar-se-ia como a fase de Conceituação Abstrata. E, completando o ciclo, a experimentação ativa seria representada pela adaptação do rumo das decisões, em face dos resultados obtidos.

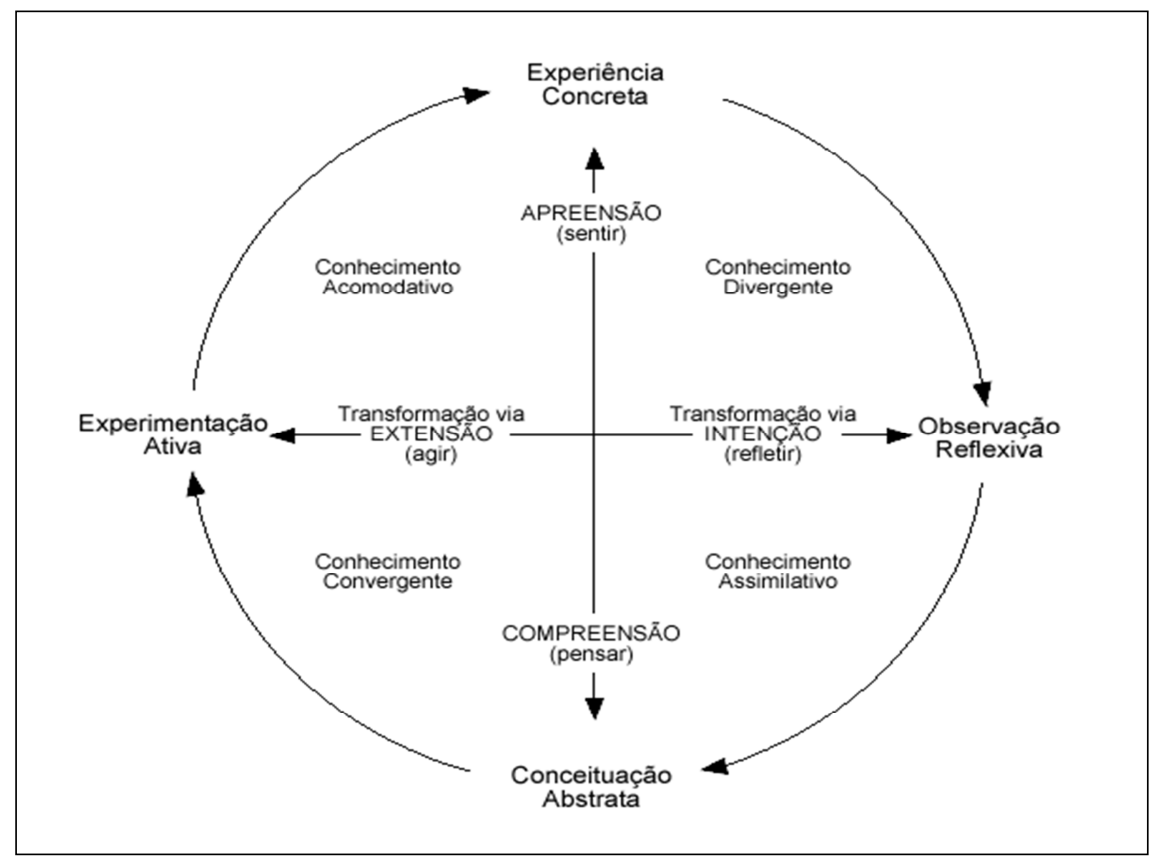

Figura 1. Ciclo da Aprendizagem Vivencial e as Formas de Conhecimento Relacionadas.

Fonte: Adaptado de Kolb, D. A. (1984). Experimental Learning: experience as the source of learning and development (p. 42). New Jersey: Prentice Hall.

Com base neste referencial sobre as bases para o aprendizado a partir da utilização da técnica de jogos de empresas, parte-se para a explicação sobre os procedimentos adotados na pesquisa. Nesta parte, tem-se o intuito de verificar, a partir do discurso coletivo de alunos, qual o significado dessa técnica no processo de aprendizagem em Administração.

\section{Procedimentos Metodológicos}

Os sujeitos deste estudo foram 72 alunos matriculados nos dois últimos períodos dos cursos de graduação em Administração e em cursos de pós-graduação (especialização) em Administração ou áreas correlatas. Em ambos os casos, as IES (duas públicas federais e duas particulares) eram credenciadas pelo MEC, e os cursos, devidamente autorizados. Das quatro turmas, duas eram de graduação, e as outras duas, de cursos de especialização. Com a finalidade de caracterizar a pesquisa como um estudo cujos resultados circunscrevem-se a uma situação específica, descrevem-se a seguir os passos adotados na experiência que antecedeu o levantamento dos dados. 
Os procedimentos foram realizados no período de novembro de 2008 a janeiro de 2009 , ocorrendo de forma idêntica com as diversas turmas, inclusive com a utilização dos mesmos dois moderadores, para evitar vieses nos resultados da pesquisa. Inicialmente o simulador do jogo de empresas era apresentado à turma, num primeiro encontro, no qual os moderadores respondiam às dúvidas dos alunos e procediam à divisão das equipes. Estas eram compostas por quatro ou cinco membros, agrupados de acordo com os estilos de aprendizagem definidos pelo Inventário dos Estilos de Aprendizagem - IEA (Kolb, 1978).

No segundo encontro, as equipes, já formadas, analisavam os cenários e tomavam as decisões para os dois primeiros períodos (trimestres) da simulação. Com o objetivo de simular um ano completo, as equipes tomavam as decisões por mais dois períodos, o que gerava um total de quatro rodadas de decisão por experimento. Os resultados gerais eram discutidos entre os integrantes de todas as equipes com o intermédio dos moderadores e, ao final, cada aluno (jogador) respondia a um questionário não estruturado de autopreenchimento.

O jogo de empresas foi operacionalizado por meio do simulador denominado Campus do Empreendedor, que é uma iniciativa do SEBRAE e da COPPE/UFRJ, para o qual um dos moderadores foi selecionado como Beta Tester, ou seja, um usuário de teste de uma versão ainda em desenvolvimento.

O Campus do Empreendedor pode ser classificado como um simulador generalista, pois integra diversas atividades funcionais de uma indústria fictícia, neste caso específico, de bicicletas. Classificase, também, de acordo com Tanabe (1973), como interativo, já que as decisões de uma empresa afetam o desempenho das demais. Quanto ao nível de complexidade, pode ser considerado médio, por envolver 16 variáveis divididas em sete grandes áreas: (a) compra de pesquisa; (b) recursos humanos; (c) operações; (d) produção e insumos; (e) marketing e estratégia; (f) empréstimos; (g) preço.

Numa turma, cada equipe formada era responsável pela gestão de uma das empresas concorrentes, e a quantidade total de concorrentes era igual ao número de equipes formadas por turma, sendo seis equipes em uma turma de graduação (com 26 alunos), quatro na outra (com 19 alunos), três equipes em uma turma de especialização (com 15 alunos) oito na outra (com 33 alunos). Todas as equipes obedeceram ao mesmo cronograma de atividades.

O instrumento de coleta de dados continha duas questões de respostas abertas às quais os alunos eram convidados a responder com base na experiência vivida: uma sobre qual a percepção a respeito do que é um jogo de empresas; e a outra acerca de qual a contribuição do jogo para o seu aprendizado sobre gestão empresarial. Por limitações de espaço, neste artigo serão analisadas, qualitativa e quantitativamente, apenas as respostas relativas à pergunta: "Para você, que é jogo de empresas?", de acordo com a metodologia do Discurso do Sujeito Coletivo (DSC).

Baseado nos pressupostos da Teoria das Representações Sociais (Jodelete, 1989), o Discurso do Sujeito Coletivo (DSC) constitui-se numa proposta metodológica em que se propõe contemplar informações comuns a distintos discursos individuais, reconstruindo-os num pensamento coletivo diferente de outros discursos relacionados. Ao final do processo, buscam-se como resultado depoimentos coletivos construídos a partir de trechos de distintos depoimentos individuais. Esses depoimentos coletivos escritos na primeira pessoa do singular visam produzir, no receptor, o efeito de um posicionamento coletivo (Lefevre \& Lefevre, 2003, 2006). Assim, o discurso do sujeito coletivo, enquanto estratégia metodológica, propõe-se a reconstruir um ser ou entidade empírica coletiva opinante na forma de um sujeito de discurso emitido na primeira pessoa (Lefevre \& Lefevre, 2006).

Conforme descrita por Lefevre e Lefevre (2003), a técnica do DSC consiste em um conjunto de procedimentos de tabulação e organização de dados discursivos provenientes, em geral, de depoimentos orais. Todavia, os próprios autores destacam que qualquer material apresentado de forma textual pode ser base para uso da técnica. Na presente pesquisa, foram utilizados depoimentos provenientes dos questionários anteriormente mencionados. Após um procedimento de tratamento do 
material da pesquisa, 21 questionários foram descartados por apresentarem respostas ilegíveis ou ausência de respostas, restando 72 questionários a serem analisados, dos 93 coletados.

Para a criação do Discurso do Sujeito Coletivo, foram executadas as seguintes operações a partir dos discursos coletados, utilizando-se o software MS Excel:

1. O processo se iniciou com a seleção das Expressões-Chave (E-Ch) de cada discurso (respostas dadas à questão 01 do instrumento de coleta). Cada expressão-chave, segmentos, contínuos ou descontínuos, de discurso, revela o cerne das respostas;

2. Passou-se então à identificação da Ideia Central (IC) de cada uma das expressões-chave selecionadas no passo anterior. Uma IC é a síntese do conteúdo das E-Ch, em outras palavras, o seu significado real (embora algumas vezes oculto no discurso). Foram identificadas as ideias centrais semelhantes ou complementares, criando etiquetas (A, B, C, etc.) que identificavam os grupos de ICs (IC-A, IC-B, IC-C, etc.);

3. Finalmente, as expressões-chave ligadas às ideias centrais semelhantes ou complementares foram reunidas em um discurso síntese que é o discurso do sujeito coletivo (DSC). A discursividade, isto é, o encadeamento lógico e harmônico dos conteúdos ideativos e de suas justificativas ou argumentos, presentes nas expressões-chave selecionadas, foi mantida, por tratar-se de peça fundamental para o DSC.

De acordo com o método utilizado, houve a necessidade de efetuar uma limpeza de trechos que caracterizavam particularidades do discurso individual (nomes próprios, situações específicas, etc.) e, de modo que apresentasse uma estrutura sequencial clara e coerente, os discursos foram encadeados narrativamente, ou seja, os componentes do DSC foram ligados por elementos textuais (conjunções, pronomes, artigos, etc.) sem modificar o conteúdo (significado) original.

É importante destacar que a técnica original prevê a possibilidade de elaboração dos DSCs a partir de outros operadores metodológicos, as Ancoragens (AC), que são a manifestação explícita de uma teoria, ideologia ou crença, podendo ser também entendidas como uma afirmação genérica usada para enquadrar uma situação específica. Mas, essa metodologia não foi utilizada no presente artigo, por se entender que não agregaria elementos à análise.

Para os criadores da técnica, um DSC é válido quando reflete um discurso plausível, capaz de provocar um sentimento no leitor ou interlocutor, de que uma pessoa real, concreta, existente, poderia ter proferido, validamente, o dito DSC, que é adequadamente decodificado pelo receptor. Adicionalmente, pelo ponto de vista da Teoria da Representação Social, o DSC é válido quando sugere um discurso compartilhado por sujeitos reais em interações sociais correntes.

Segundo Teixeira e Lefevre (2008), o DSC representa um método que torna mais claras e expressivas as representações sociais, permitindo que um determinado grupo social (neste artigo, alunos de graduação e pós-graduação) possa ser visto como autor e emissor de discursos comuns, não necessariamente concordantes, mas complementares.

A utilização do DSC como método de pesquisa se dá desde 1990, mas tem-se destacado a partir de 2005, após seu amadurecimento (Lefevre \& Lefevre, 2006). Uma análise do Banco de Dados de DSC do Instituto de Pesquisas do Discurso do Sujeito Coletivo (IPDSC) - apontou 735 registros em 10 de dezembro de 2008, sendo 440 a partir de 2005, o que demonstra um crescimento de sua utilização, que é predominante no campo das Ciências da Saúde, área na qual a técnica se originou, mas já há trabalhos nas áreas de Ciências Humanas e Sociais Aplicadas. A análise dos dados, demonstrada a seguir, foi desenvolvida com base na revisão de literatura apresentada anteriormente. 


\section{Análise dos Resultados}

O tratamento quantitativo do material coletado, inicialmente, analisou a frequência em que os discursos individuais eram classificados de acordo com as Ideias Centrais (IC). Como uma única resposta pode conter mais de uma IC, o somatório da frequência das ideias centrais foi superior à quantidade de respostas obtidas. Foram identificadas 11 ICs distintas para a questão relativa à percepção sobre o jogo, e todas elas estavam presentes, tanto nos discursos dos alunos de graduação quanto nos discursos dos alunos de pós-graduação. Suas respectivas frequências, distinguidas por nível acadêmico (graduação e pós-graduação), podem ser observadas na Tabela 1.

Tabela 1

\section{Frequência por Ideia Central}

\begin{tabular}{|c|c|c|c|c|}
\hline & & Grad. & Pós & Total \\
\hline IC-A & O jogo de empresas auxilia no treinamento do processo decisório. & 21 & 12 & 33 \\
\hline IC-B & O jogo de empresas oferece a vivência de experiências simuladas. & 16 & 16 & 32 \\
\hline IC-C & $\begin{array}{l}\text { O jogo de empresas é um instrumento que proporciona o desenvolvimento de } \\
\text { habilidades para o trabalho em equipe. }\end{array}$ & 8 & 4 & 12 \\
\hline IC-D & O jogo de empresas é uma competição. & 1 & 8 & 9 \\
\hline IC-E & O jogo de empresas estimula o empreendedorismo. & 1 & 5 & 6 \\
\hline IC-F & $\begin{array}{l}\text { O jogo de empresas é a aplicação prática dos conhecimentos adquiridos no curso } \\
\text { de Administração. }\end{array}$ & 11 & 2 & 13 \\
\hline IC-G & O jogo de empresas permite uma visão ampliada da empresa. & 6 & 1 & 7 \\
\hline IC-H & O jogo de empresas é um estímulo à aquisição de novos conhecimentos. & 2 & 2 & 4 \\
\hline IC-I & O jogo de empresas é uma forma de aprendizado por tentativa e erro. & 3 & 2 & 5 \\
\hline IC-J & O jogo de empresas é a prática da análise das informações organizacionais. & 3 & 4 & 7 \\
\hline IC-K & O jogo de empresas é uma metodologia de ensino inovadora e lúdica. & 1 & 2 & 3 \\
\hline & Total & 73 & 60 & 133 \\
\hline
\end{tabular}

Nota. Fonte: elaborado pelos autores.

Foram selecionadas as categorias que apresentavam maior representatividade numérica, o que significa que esta pesquisa enfatizou a análise dos itens com maior recorrência nos discursos individuais dos alunos. Assim, para os alunos de graduação, as categorias IC-A, IC-B, IC-F e IC-C foram mais frequentes (em ordem decrescente de frequência). Já para os alunos de pós-graduação, as mais frequentes foram as categorias IC-B, IC-A e IC-D (também em ordem decrescente de frequência). Desta forma, tem-se as categorias IC-A, IC-B, IC-C, IC-D e IC-F como as mais recorrentes nos discursos dos alunos de graduação e pós-graduação.

Posteriormente, com base nesta análise de frequências, procedeu-se um teste para comparação de proporções das ideias centrais (ICs) mais recorrentes, tanto nos discursos dos alunos de graduação quanto nos de pós-graduação, com o intuito de verificar se tais proporções eram significativamente diferentes. Os dados para esta análise estão apresentados na Tabela 2. 
Tabela 2

Teste para Comparação de Proporções

\begin{tabular}{lccccccc}
\hline & Graduação & Pós-graduação & Total & $\begin{array}{c}\text { Proporção } \\
\text { Graduação }\end{array}$ & $\begin{array}{c}\text { Proporção } \\
\text { Pós-graduação }\end{array}$ & $\mathbf{Z}$ & Pvalor \\
\hline IC-A & 21 & 12 & 33 & 0,567568 & 0,333333 & 2,069856 & 0,019233 \\
\hline IC-B & 16 & 16 & 32 & 0,432432 & 0,444444 & $-0,10341$ & 0,458817 \\
\hline IC-C & 8 & 4 & 12 & 0,216216 & 0,111111 & 1,228173 & 0,109691 \\
\hline IC-D & 1 & 8 & 9 & 0,027027 & 0,222222 & $-2,62919$ & 0,004279 \\
\hline IC-F & 11 & 2 & 13 & 0,297297 & 0,055556 & 2,868192 & 0,002064 \\
\hline
\end{tabular}

Nota. Fonte: elaborado pelos autores.

Observa-se que as categorias IC-A, IC-D e IC-F rejeitam a hipótese nula de igualdade de proporções. Ou seja, é possível afirmar, ao nível de $95 \%$ de confiabilidade, que as proporções de respostas dos alunos de graduação e pós-graduação são significativamente diferentes para essas ideias centrais. Por outro lado, as categorias IC-B e IC-C, utilizando o mesmo processo de análise, têm proporções diferentes, as quais não são consideradas estatisticamente significativas.

A partir desta análise quantitativa, passa-se à construção e à análise qualitativa dos DSCs dos alunos. Aquelas ideias centrais, cujas proporções de respostas dos estudantes de graduação e pósgraduação foram consideradas iguais, constituíram um único DSC, enquanto as demais foram tratadas isoladamente, de acordo com o nível de formação do respondente, para a identificação de semelhanças e diferenças nos discursos.

Na Tabela 3, é apresentado o DSC, de acordo com o significado que os alunos atribuem à técnica de jogo de empresas, no que tange a IC-A, separados por nível de formação.

Tabela 3

IC-A

Ideia Central

O jogo de empresas auxilia no treinamento do processo decisório.

\begin{tabular}{|c|c|}
\hline Graduação & Pós-graduação \\
\hline $\begin{array}{l}\text { É uma dinâmica utilizada para repassar os conhecimentos adquiridos, seja } \\
\text { em alguma empresa na qual se trabalha, ou de teorias aprendidas em sala } \\
\text { de aula, em que se poderá testar a capacidade de tomada de decisões. É } \\
\text { uma ferramenta para treinamento, na qual eu tenho a oportunidade de } \\
\text { testar, de modo prático e estruturado, meu poder de decisão. Isso me } \\
\text { estimula a tomar decisões constantemente, fazendo análise das decisões } \\
\text { tomadas e de seus impactos na organização, para ver a responsabilidade } \\
\text { destas, porque as mesmas acabam impactando nas principais áreas da } \\
\text { Administração: RH, Marketing, Produção, Administração Estratégica, } \\
\text { Financeira. Essa simulação permite que os participantes do jogo vivenciem } \\
\text { situações de incerteza, nas quais é necessário tomar decisões o tempo todo } \\
\text { diante do mercado e a respeito de investimentos, verificando a influência } \\
\text { das variáveis do próprio mercado e os resultados de nossas decisões. No } \\
\text { jogo, é preciso avaliar suas práticas, estratégias, o ambiente em que se atua } \\
\text { e seus concorrentes para, assim, procurar tomar as melhores decisões. }\end{array}$ & $\begin{array}{l}\text { O jogo é uma maneira de nos } \\
\text { familiarizarmos com o mundo dos } \\
\text { negócios, sabendo como tomar } \\
\text { decisões mais precisas na hora } \\
\text { certa. Desenvolve, assim, a } \\
\text { habilidade para tomada de decisões } \\
\text { dentro de uma empresa hipotética, } \\
\text { envolvendo todas as suas etapas de } \\
\text { produção, desde o planejamento até } \\
\text { a venda. É um sistema que } \\
\text { disponibiliza aos participantes, } \\
\text { organizados em equipes, a interação } \\
\text { através da tomada de decisões e a } \\
\text { avaliação dos resultados gerados. }\end{array}$ \\
\hline
\end{tabular}

Nota. Fonte: elaborado pelos autores. 
Tem-se, assim, que a percepção dos alunos reflete grande parte dos estudos sobre a aplicação de jogos de empresas, já que sua maioria percebe a capacidade da técnica relacionada ao treinamento para a tomada de decisões. Apesar de, estatisticamente, as proporções das respostas de alunos de graduação e de pós-graduação serem significativamente diferentes, a partir dos DSCs formados, percebe-se que ambos mantêm uma forte relação, quando se busca interpretar o significado atribuído aos jogos de empresas. Por vezes, este significado está associado a uma técnica educacional, sendo expresso pelo uso de termos como dinâmica e simulação, no DSC de alunos de graduação, e maneira, no DSC de alunos de pós-graduação. Por outras vezes, o significado está associado a recursos didáticos, expresso por termos como ferramenta, no DSC dos alunos de graduação, e sistema, no de pós-graduação.

A principal diferença que a análise separada pelo nível de formação revela é um caráter mais educacional da opinião dos alunos de graduação a respeito do significado dos jogos de empresas, frente ao caráter mais ligado a uma racionalidade instrumental dos alunos de pós-graduação.

A percepção dos alunos reflete, também, o embasamento teórico proposto neste artigo e utilizado por quase a totalidade dos pesquisadores quando se observa a técnica como uma forma de aprendizagem vivencial, mesmo que a experiência seja simulada. Como pode ser observado na Tabela 4, o discurso coletivo aborda o significado do jogo como vivência simulada de atividades empresariais.

Tabela 4

IC-B

Ideia Central

O jogo de empresas oferece a vivência de experiências simuladas.

Discurso do Sujeito Coletivo (graduação e pós-graduação)

O jogo de empresas é uma vivência de experiências, por meio de software que permite a simulação de atividades empresariais. Desta forma, é possível perceber o funcionamento e conhecer o ambiente de negócio de uma empresa real, já que aparecem situações nas quais você deve saber conduzir uma organização hipotética, ou seja, agir e pensar como se estivesse à frente de uma nova organização, em todos os seus processos. Trata-se de um ambiente virtual que tenta simular o dia a dia de uma empresa, sua interação com os concorrentes e a dinâmica do mercado, em que os participantes devem avaliar os resultados, através das respostas e retornos que o sistema gera. $\mathrm{O}$ jogo permite desenvolver e adquirir experiências em questões ligadas à atividade empresarial, integrando as áreas da administração. Assim, proporciona aprendizado com reflexão, prática e familiarização com o mundo dos negócios.

Nota. Fonte: elaborado pelos autores.

Nesse DSC composto pelos dois níveis de formação, verificam-se elementos que remetem ao conceito da aprendizagem vivencial conforme discutida por Kolb (1984). Expressões como vivência de experiências, simulação de atividades, desenvolver e adquirir experiências e simular o dia a dia estão presentes no discurso. Tais dados também corroboram com as afirmações de Arbex, Corrêa, Melo, Ribas e Lopes (2006) e Sauaia (2008), anteriormente apresentadas, pois observa-se, pelo discurso coletivo, que há uma experimentação dos instrumentos de análise, formulação e controle gerencial. Os alunos são expostos às diversas variáveis em diferentes contextos ambientais controláveis e não controláveis, e precisam gerar respostas a tais fatores através da tomada de decisões em situações de incerteza.

Outro aspecto muito recorrente nos discursos individuais dos alunos e que, por isso, compuseram o discurso coletivo (Tabela 5), é a capacidade da técnica para desenvolver habilidades para o trabalho em equipe. Esse aspecto é particularmente interessante de ser observado, pois tal (habilidade humana) é uma das três necessárias ao exercício da atividade profissional do Administrador, segundo Katz (1974), além das habilidades conceituais e técnicas. 
Tabela 5

IC-C

\section{Ideia Central}

O jogo de empresas é um instrumento que proporciona o desenvolvimento de habilidades para o trabalho em equipe.

\section{Discurso do Sujeito Coletivo (graduação e pós-graduação)}

Jogo de empresas é um instrumento que proporciona, no contexto acadêmico, a integração do grupo, o que é muito importante. É um método que disponibiliza aos participantes a capacidade de desenvolver seus conhecimentos em trabalho em equipe. Pode-se aprender ou colocar em prática o trabalho em equipe, visto que todas as informações adquiridas para se chegar a um resultado específico passam pelo conhecimento do grupo. $\mathrm{O}$ participante (jogador) tem a oportunidade de verificar suas atitudes, inclusive seu comportamento diante de uma equipe e o seu envolvimento com a mesma. Todos os funcionários, incluindo a alta direção, participam direta ou indiretamente nos resultados. É uma boa oportunidade de interação entre componentes e suas contribuições, o que incentiva o trabalho em equipe.

Nota. Fonte: elaborado pelos autores.

Verifica-se que os estudantes relacionam o jogo de empresas com a capacidade para o efetivo trabalho como membro de um grupo e para a construção cooperativa de esforços no grupo que o administrador lidera. Evidencia-se assim, a contribuição dos jogos para a experimentação do trabalho em grupo e, desta forma, a necessidade da competência para lidar com pessoas, ou habilidades humanas, conforme definido por Katz (1974).

Tem-se ainda que o DSC, construído a partir da ideia central D (IC-D), revela a noção do jogo de empresas como uma competição, conforme exposto na Tabela 6. A noção de superar os concorrentes (no jogo ou em sala de aula) é marcada por expressões como batalha, disputa, competitividade.

Tabela 6

\section{IC-D}

\section{Ideia Central}

O jogo de empresas é uma competição.

\section{Discurso do Sujeito Coletivo}

\begin{tabular}{|c|c|}
\hline Graduação & Pós-graduação \\
\hline $\begin{array}{l}\text { O jogo é pra quem quer vencer } \\
\text { a batalha da produtividade, da } \\
\text { comunicação, do trabalho em } \\
\text { equipe e da liderança. }\end{array}$ & $\begin{array}{l}\text { Jogo de empresas é uma modalidade de disputa acadêmico-lúdica, entre equipes } \\
\text { (concorrentes), com fins didáticos, que visa retratar a competitividade entre } \\
\text { empresas. Um jogo de estratégia, no qual é preciso disputar com a concorrência } \\
\text { pelo preço, lucro, marketing e clientes, para saber quem vai ganhar mercado. }\end{array}$ \\
\hline
\end{tabular}

Nota. Fonte: elaborado pelos autores.

Percebe-se que, embora separados pelos critérios estatísticos delineados anteriormente, os discursos dos níveis de graduação e pós-graduação são bastante semelhantes. Destaca-se que, neste trabalho, a percepção do jogo como competição é fortemente influenciada pelo tipo de regra do simulador utilizado na experiência, ou seja, não há possibilidade de cooperação entre as empresas/equipes. Pelas regras, os grupos são compelidos a formatar estratégias competitivas para atingir os objetivos propostos pela atividade. Finalmente, há, ainda, o enfoque dado pelos alunos ao significado dos jogos de empresas como técnica responsável pela aplicação dos conceitos adquiridos no curso de administração, como pode ser observado na Tabela 7. 
Tabela 7

IC-F

Ideia Central

O jogo de empresas é a aplicação prática dos conhecimentos adquiridos no curso de Administração.

Discurso do Sujeito Coletivo

\begin{tabular}{l|l}
\hline Graduação & Pós-graduação \\
\hline Uma forma prática de ver tudo o que estudamos na faculdade e de aplicar o & $\begin{array}{l}\text { É uma forma de pôr em } \\
\text { prática o aprendizado que }\end{array}$ \\
nosso poder de decisão, nível de conhecimento e análise do ambiente, sem \\
contar o trabalho em equipe. É uma ferramenta que aproxima a base conceitual \\
você constrói com as teorias \\
do aluno à prática de tomada de decisões em um ambiente organizacional \\
simuladas e com o conhecimento. \\
possibilitando estreitar a visão da teoria com a prática, de forma dinâmica. & \\
\hline
\end{tabular}

Nota. Fonte: elaborado pelos autores.

Por esse discurso coletivo, percebe-se a noção de jogos de empresas como aproximadores da teoria e da prática administrativa. Embora com maior representação da ideia central no nível de graduação, em ambos os casos o discurso remete à percepção do jogo como um meio para experimentar na prática os conhecimentos aprendidos ao longo dos cursos de formação, embora não sejam especificados nos discursos quais foram as noções (teorias, conceitos, fórmulas, etc.) necessárias para o desempenho da atividade.

A seguir são delineadas as considerações finais que buscam sumarizar as discussões dos resultados e da revisão de literatura.

\section{Considerações Finais}

A adoção de jogos de empresas como técnica para o ensino de administração foi tardia no caso brasileiro, com as primeiras experiências datando da década de 1970, sendo que só ocorreu de forma mais ampla a partir do ano 2000, como constatado por Bernard (2006), Arbex et al. (2006), Neves e Lopes (2008) e Motta (2009). Todavia, observa-se no Brasil uma crescente utilização de jogos, em especial nos cursos de graduação em Administração. Por conta disso, pesquisas mais aprofundadas, a exemplo desta, sobre a contribuição da técnica de ensino em destaque para a formação de administradores devem ser realizadas, de maneira que contribuam para a reflexão sobre a adoção dessa prática docente. Indica-se, de antemão, a intenção de empreender uma análise a partir das respostas não utilizadas nessa pesquisa sobre a contribuição da técnica para o aprendizado sobre gestão empresarial.

A percepção dos estudantes de graduação ou pós-graduação das quatro instituições de ensino que participaram da pesquisa ressalta o caráter vivencial da técnica e corrobora a maioria das pesquisas já desenvolvidas na área de que há um auxílio maior no desenvolvimento de habilidades técnicas e humanas, e menor para habilidades conceituais. Embora haja declarações individuais dos alunos pesquisados relacionadas ao estímulo à aquisição de novos conhecimentos, a capacidade da técnica para agregar conhecimentos sobre Administração não pôde ser comprovada. Suspeita-se que, mesmo o jogo apresentando problemas autênticos do campo da Administração, para os quais haveria a necessidade de se buscar novos conhecimentos para a definitiva solução deles, o simulador permite que as decisões sejam lançadas sem embasamento teórico. 
A partir do discurso do sujeito coletivo, constata-se que a percepção dos estudantes a respeito do jogo de empresas está fortemente integrada às suas contribuições para o processo de aprendizagem em administração. Foram identificados fatores tais como:

Auxílio no treinamento para o processo decisório. No processo formativo em Administração, geralmente não é permitido ao aluno experimentar os efeitos reais das decisões gerenciais, possibilitados somente pela prática. Dentre outros achados, verificou-se que os jogos de empresas foram apontados como uma técnica complementar, que contribui para a formação gerencial.

Vivência simulada das atividades empresariais. Permitindo a experimentação de inúmeras decisões estratégicas, livre dos riscos de uma decisão errada, os jogos de empresas se configuram, para o autor, como uma importante ferramenta de treinamento gerencial para a formulação de estratégias empresariais.

Desenvolvimento de habilidades interpessoais para o trabalho em equipe. Esse resultado reforça as conclusões de Goldschmidt (1977), sobre o estímulo ao trabalho em equipe gerado através dos jogos, e de Sauaia (1995), para quem o trabalho em grupo prevalece na aprendizagem com o uso da técnica.

Aplicação dos conhecimentos adquiridos ao longo do curso de Administração. O que vai ao encontro de planos de ensino, cuja abordagem é a de integração das diversas disciplinas específicas de gestão.

Assim, a não comprovação da capacidade dos jogos para a aquisição de novos conhecimentos, não o invalida como técnica de ensino e aprendizagem em Administração, principalmente pelo fato de proporcionar o desenvolvimento de outras habilidades necessárias ao profissional administrador. Adicionalmente, o estudo aponta que o conhecimento da lógica econômica e da pesquisa aplicada ao papel gerencial combinadas com a tomada de decisões sob incerteza proposta no jogo de empresas é capaz de promover um processo de aprendizagem significativa por meio da ação, vivenciada no ciclo de Kolb (1984).

É importante ressaltar que o fato de os alunos terem sido submetidos a uma experiência anterior à coleta de dados, deu-se pela necessidade de garantir que todos os respondentes já tivessem vivenciado um jogo de empresas para poder responder a questões relativas à técnica. Entretanto, foram encontradas delimitações das respostas dos alunos que caracterizam uma limitação desta pesquisa. Como foi utilizado um simulador baseado em computador, o significado do jogo esteve atrelado a essa forma de aplicação e não a outras possíveis, como jogos de tabuleiro, jogos de sala de aula, livro jogo, etc. Igualmente, pelo fato de ser um jogo geral, não apareceram respostas relativas aos jogos funcionais. Tem-se ainda que a natureza competitiva das regras do simulador utilizado, de certa forma, condicionou a visão dos respondentes ao jogo como uma disputa, enquanto outras possibilidades (cooperação, por exemplo) não foram enunciadas. Dessa forma, sugere-se que sejam aplicadas, em outras pesquisas, formas variadas de jogos, para uma posterior coleta de dados.

Destaca-se que, de maneira inusitada, a separação dos alunos de graduação e de pós-graduação nas análises não forneceu elementos significativos de diferenciação entre os grupos. Ou seja, ainda que a frequência de uma IC tenha sido quantitativamente significativa entre estes grupos, como, por exemplo, a IC-D, a verificação analítica evidenciou a aproximação dos discursos.

Ademais, ressalta-se que os resultados obtidos nesta pesquisa fazem referência a uma situação particular, limitando-se a um contexto específico. Possíveis generalizações das conclusões levantadas carecem de novas pesquisas, ampliando-se e diversificando mais intensamente a amostra. Outra sugestão é incluir os níveis de estudo de mestrado e doutorado, nos quais os jogos de empresas também sejam utilizados didaticamente.

Finalmente, o elevado nível de satisfação dos alunos com a aplicação da técnica de jogos de empresas, identificado nesta pesquisa, estimula o envolvimento deles na atividade, o que favorece a 
aprendizagem. Isso se deve ao caráter lúdico e vivencial da técnica, o que é desejado pelos alunos do curso de Administração e, de maneira análoga, estimula novas pesquisas com o tema.

Artigo recebido em 22.02.2011. Aprovado em 27.03.2012.

\section{Referências}

Anderson, P. H., \& Lawton, L. (2007). Simulation performance and its effectiveness as a PBL problem: a follow-up study. Developments in Business Simulation and Experimental Learning, 34(1), 43-50.

Arbex, M. A., Corrêa, H. P., Melo, A., Jr., Ribas, C. A., \& Lopes, P. C. (2006, setembro). O uso de jogos de empresas em cursos de graduação em administração e seu valor pedagógico: um levantamento no estado do Paraná. Anais do Encontro Nacional da Associação Nacional de Pós-Graduação e Pesquisa em Administração, Salvador, BA, Brasil, 30.

Banta, T., Black, K., \& Kline, K. (2000). Plenary address offers evidence for and against problembased learning. PBL Insights, 3(3), 1-7.

Beppu, C. I. (1984). Simulação em forma de "jogo de empresas" aplicada ao ensino da Contabilidade (Dissertação de mestrado). Universidade de São Paulo, São Paulo, SP, Brasil.

Berbel, N. A. (1998). Problematização e a aprendizagem baseada em problemas: diferentes termos ou diferentes caminhos? Interface - Comunicação, Saúde, Educação, 2(2), 139-154. doi: 10.1590/S1414-32831998000100008

Bernard, R. R. S. (2006, agosto). Estrutura de utilização dos jogos de empresas nos cursos de graduação em administração e ciências contábeis do país e avaliações preliminares de uma disciplina baseada neste método. Anais do Encontro Nacional dos Cursos de Graduação em Administração, São Luiz, MA, Brasil, 17.

Bertero, C. O. (2006). Ensino e pesquisa em administração. São Paulo: Thomson Learning.

Gil, A. C. (1997). Metodologia do ensino superior (3a ed.). São Paulo: Atlas.

Goldschmidt, P. C. (1977). Simulação e jogo de empresas. Revista de Administração de Empresas, 17(3), 43-46.

Instituto Nacional de Estudos e Pesquisas Educacionais Anísio Teixeira. (2006). Sinopses estatísticas da educação superior - graduação. Brasília, DF, Brasil. Recuperado de http://portal.inep.gov.br/superior-censosuperior-sinopse

Jodelete, D. (1989). Répresentations sociales: um domaine en expansion. In D. Jodelete (Org.), Representations socials (pp. 31-61). Paris: PUF.

Katz, R. (1974). Skills of an effective administrator. Harvard Business Review, 52(5), 90-102.

Kolb, D. A. (1978). Organizational psychology: an experimental approach. New Jersey: Prentice Hall

Kolb, D. A. (1984). Experimental learning: experiance as the source of learning and development. New Jersey: Prentice Hall.

Lacruz, A. J., \& Villela, L. E. (2006, agosto). Percepção dos participantes de jogos de empresas quanto às condições facilitadoras para o aprendizado em programas de simulação empresarial: 
um estudo exploratório. Anais do Seminário de Administração da Universidade de São Paulo, São Paulo, SP, Brasil, 9.

Lefevre F., \& Lefevre A. M. (2003). O discurso do sujeito coletivo: um novo enfoque em pesquisa qualitativa - desdobramentos. Caxias do Sul: Educs.

Lefevre, F, \& Lefevre, A. M. (2005). Depoimentos e discursos: uma proposta de análise em pesquisa social. Brasília: Líber Livro.

Lefevre, F., \& Lefevre, A. M. (2006). O sujeito coletivo que fala. Revista Interface - Comunicação, Saúde, Educação, 10(20), 517-524. doi: 10.1590/S1414-32832006000200017

Li, E., \& Baillie, A. (1993). Mixing case method with business game: student evaluations. Simulation \& Gaming, 24(3), 336-355. doi: 10.1177/1046878193243006

Libâneo, J. C. (1994). Didática. São Paulo: Cortez.

Lopes, P. C. (2001). Formação de administradores: uma abordagem estrutural e técnico didática (Tese de doutorado). Universidade Federal de Santa Catarina, Florianópolis, SC, Brasil.

Martinelli, D. P. (1987). A utilização de jogos de empresas no ensino de Administração (Dissertação de mestrado). Universidade de São Paulo, São Paulo, SP, Brasil.

Mendes, J. B. (2000, outubro). A utilização de jogos de empresas no ensino da contabilidade - uma experiência no curso de ciências contábeis da Universidade Federal de Uberlândia. Anais do Congresso Brasileiro de Contabilidade, Goiânia, GO, Brasil, 16.

Motta, G. S. (2009). Panorama da aplicação da técnica de jogos de empresas para a formação em administração nas instituições de ensino superior da Bahia (Dissertação de mestrado). Universidade Federal da Bahia, Salvador, BA, Brasil.

Nagamatsu, F. A., Fedichina, M. A. H., Gozzi, S., \& Boldrin, V. P. (2006, agosto). A aplicação do jogo de empresas no desenvolvimento gerencial: um estudo aplicado em cursos de graduação e de pós-graduação (nível lato sensu). Anais do Seminário de Administração da Universidade de São Paulo, São Paulo, SP, Brasil, 9.

Neves, J. P., \& Lopes, P. C. (2008, setembro). Jogos de empresas: um estudo da utilização em cursos de graduação em administração no estado de São Paulo. Anais do Encontro Nacional da Associação Nacional de Pós-Graduação e Pesquisa em Administração, Rio de Janeiro, RJ, Brasil, 32.

Olivier, M., \& Rosas, A. R. (2004, agosto). Jogos de empresas na graduação e no mestrado. Anais do Seminário de Administração da Universidade de São Paulo, São Paulo, SP, Brasil, 7.

Paixão, R. B., Bruni, A. L., \& Carvalho, C. V. O., Jr. (2007, agosto). Jogos de empresas na academia: aspectos conceituais e metodológicos de uma amostragem de publicações brasileiras entre 1998 e 2006. Anais do Seminário de Administração da Universidade de São Paulo, São Paulo, SP, Brasil, 10.

Peixoto, R., Veloso, E., \& Lopes, J. (2003, setembro). Fragilidades na mensuração de aprendizagem em jogos de empresas: uma reflexão. Anais do Encontro Nacional da Associação Nacional de Pós-Graduação e Pesquisa em Administração, Atibaia, SP, Brasil, 27.

Pereira, M. (2005). Ensino-aprendizagem em um contexto dinâmico: o caso de planejamento de transportes (Tese de doutorado). Universidade de São Paulo, São Carlos, SP, Brasil.

Ribeiro, L. R. (2005). A aprendizagem baseada em problemas (PBL). São Carlos: UFSCar. 
Ribeiro, L. R., \& Mizukami, M. G. (2004). Uma implementação da aprendizagem baseada em problemas (PBL) na pós-graduação em engenharia sob a ótica dos alunos. Semina: Ciências Sociais e Humanas, 25(1), 89-102.

Sauaia, A. C. A. (1990). Jogos de empresas: tecnologia e aplicação (Dissertação de mestrado). Universidade de São Paulo, São Paulo, SP, Brasil.

Sauaia, A. C. A. (1995). Satisfação e aprendizagem em jogos de empresas: contribuições para a educação gerencial (Tese de doutorado). Universidade de São Paulo, São Paulo, SP, Brasil.

Sauaia, A. C. A. (2006). Conhecimento versus desempenho das organizações: um estudo empírico com jogos de empresas. Revista Eletrônica de Administração, 12(1), 1-17. Recuperado de http://read.adm.ufrgs.br/edicoes/pdf/artigo_385.zip.

Sauaia, A. C. A. (2008). Laboratório de gestão: simulador organizacional, jogo de empresas e pesquisa aplicada. Barueri: Manole.

Saviani, N. (1998). Saber escolar, currículo e didática: problemas da unidade conteúdo/método no processo pedagógico (2a ed.). Campinas, SP: Autores Associados.

Sheizi, C. F., \& Santos, L. P. G. (2003, setembro). Jogos de empresas: um estudo exploratório sobre a percepção e o desempenho dos alunos dos cursos de administração e ciências contábeis. Anais do Encontro Nacional da Associação Nacional de Pós-Graduação e Pesquisa em Administração, Atibaia, SP, Brasil, 27.

Stahl, L. M., \& Lopes, P. C. (2004, setembro). Estratégias de avaliação para jogos de empresas gerais: avaliando desempenho ou aprendizagem. Anais do Encontro Nacional da Associação Nacional de Pós-Graduação e Pesquisa em Administração, Curitiba, PR, Brasil, 28.

Tanabe, M. (1973) Jogos de empresas (Dissertação de mestrado). Universidade de São Paulo, São Paulo, SP, Brasil.

Teixeira, J. J. V., \& Lefevre, F. (2008). Significado da intervenção médica e da fé religiosa para o paciente idoso com câncer. Ciência \& Saúde Coletiva, 13(4), 1247-1256. doi: 10.1590/S141381232008000400021

Thorelli, H. (2001). Ecology of international business simulation games. Simulation \& Gaming, 32(4), 492-506. doi: 10.1177/104687810103200406

Warschauer, C. L. (1977). Jogos de empresas na área de produção: programação e controle da produção. Revista de Administração de Empresas, 17(3), 47-48.

Zajdsznajder, L. (1981, setembro). Experiências educacionais no ensino de administração. Anais do Encontro Nacional da Associação Nacional de Pós-Graduação e Pesquisa em Administração, São Paulo, SP, Brasil, 5. 